\title{
Caracterização do ano hidrológico de Palmas/TO
}

A engenharia por muito tempo foi um segmento profissional heterogêneo e prioritariamente masculino, mas esse cenário tem passado por mudanças significativas. Ainda existem grandes desafios a serem superados para que a engenharia se torne um setor profissional com igualdade de gênero. Todavia, o aumento na participação feminina já é um indício da tendência positiva que toma o Brasil na busca pelo fim das desigualdades de gênero e pelo empoderamento das mulheres e meninas, como é proposto na Agenda 2030 da ONU. Nessa perspectiva, o objetivo dessa pesquisa foi identificar o perfil das mulheres profissionais de engenharia no Tocantins e analisar a sua presença e participação, com base nos dados de registros profissionais do CREA/TO. Os dados constatam que a taxa de crescimento no Estado foi de $14,9 \%$ ao longo de 55 anos (1966 a 2020) e que a média de idade das mulheres registradas diminuiu ao longo dos anos: até os anos 2000 a idade média de registro era de 29,7 anos, passou a ser de 26,8 entre 2001 e 2010 e a 26,1 entre 2011 e 2020.

Palavras-chave: Precipitação; Preenchimento de falhas; Ano hidrológico.

\section{Characterization of the hydrological year of Palmas/TO}

Several sectors of society are directly affected by the rains, so the identification and knowledge of the patterns of rainfall occurrence are essential for the planning and operation of these sectors. The reality of most municipalities in Tocantins is marked by the absence of systematized and regionalized data to assist in planning and management. Thus, the objective of this work is to characterize the hydrological year of the municipality of Palmas, based on the historical series of pluviometric stations of the National Water Agency. The histogram representing the Hydrological Year of Palmas was obtained through the analysis of the monthly totals of the average precipitation of the selected pluviometric stations. The seasonality of the Palmas Hydrological Year is well defined, characterized by two periods of six months each: the dry and the rainy period. The dry season starts in May and runs through September, while the rainy season starts in October and ends in April.

Keywords: Precipitation; Filling of faults; Hydrological year.

Topic: Engenharia de Recursos Hídricos

Reviewed anonymously in the process of blind peer.
Received: 10/11/2020

Approved: 15/02/2021

Fábio Wesley Rocha da Silva (iD

Universidade de Gurupi, Brasil

http://lattes.cnpq.br/6703832830286703

http://orcid.org/0000-0003-0616-5394

fabiowesley121@gmail.com

Alesi Teixeira Mendes

Universidade de Gurupi, Brasil

http://lattes.cnpq.br/2473113080999082

http://orcid.org/0000-0002-5632-7235

alesi@unirg.edu.br

Referencing this:

SILVA, F. W. R.; MENDES, A. T.. Caracterização do ano hidrológico de Palmas/TO. Natural Resources, v.11, n.1, p.48-55, 2021. DOI: http://doi.org/10.6008/CBPC2237-9290.2021.001.0007 


\section{INTRODUÇÃO}

Por conta das características tropicais do Brasil a absoluta maioria da precipitação do país cai sob a forma de chuva, os percentuais chegam a mais de 99\% (AYOADE, 1986). Por conta disso, convencionalmente, a medição dos volumes precipitados é pontual, realizada por meio de equipamentos denominados pluviômetros. No meio científico, por vários autores, a precipitação é tida como a variável climatológica mais importante na região tropical, e por conta da grande variabilidade espaço-temporal desse fenômeno a compreensão da sua dinâmica é fundamental para a tomada de decisões (SANTOS et al., 2001; MORAES et al., 2005).

Segundo Kobiyama et al. (2005) "a precipitação raramente é uniforme sobre uma bacia hidrográfica. Variações na intensidade e na altura total precipitada ocorrem do centro às regiões periféricas da chuva. Entretanto, a maioria dos estudos hidrológicos necessita de estimativas da precipitação média sobre a área". A variabilidade da precipitação pluvial é um importante fator no controle do ciclo hidrológico e uma das variáveis climáticas que maior influência exerce na qualidade do meio ambiente. Diversos setores da sociedade são diretamente afetados pelas chuvas: a agricultura, a pesca, a navegação, o abastecimento d'água, o manejo das águas pluviais. Deste modo, são imprescindíveis a identificação e o conhecimento dos padrões de ocorrência das chuvas para o planejamento e operação desses setores (BRITTO et al., 2008; SOARES et al., 2016).

O Tocantins possui uma economia fortemente impactada pela atividade agrícola, logo, a análise e caracterização do regime das precipitações é de fundamental importância, por exemplo, para a tomada de decisão junto às práticas agrícolas em diversas regiões do estado (OLIVEIRA FILHO et al., 2001).

Moraes et al. (2005) aponta que na Região norte do Brasil é comum que o período chuvoso seja caracterizado por precipitações de forte intensidade, enquanto no período menos chuvoso, são frequentes as estiagens de duração variável, elevando o risco das atividades agrícolas.

Marcuzzo et al. (2013) realizaram a caracterização do ano hidrológico e mapeamento espacial das chuvas nos períodos úmido e seco do estado do Tocantins. A determinação e a caracterização do ano hidrológico, bem como a distribuição espacial e o volume pluviométrico precipitado, são importantes fatores diversos estudos em pluviometria e fluviometria dentro do ciclo hidrológico de uma região.

No entanto, o estado possui grande variação espacial das precipitações em seu território, e diversos municípios em desenvolvimento dependem de informações mais pontuais para melhoria dos seus serviços. A realidade da maioria dos municípios tocantinenses é marcada pela ausência de dados sistematizados e regionalizados que auxiliem no planejamento e gestão. As prefeituras municipais raramente possuem banco de dados locais contendo os registros dos volumes precipitados, dos eventos críticos, e da dinâmica do ciclo anual das chuvas da região, mesmo que diversos setores necessitem, ou seriam beneficiados, caso houvesse a disponibilização dessas informações. Deste modo, objetivo desse trabalho foi caracterizar o ano hidrológico do município de Palmas, com base nas séries históricas de estações pluviométricas da Agência Nacional de Águas (ANA). Espera-se que com os resultados obtidos nesse trabalho os órgãos gestores municipais contem 
com mais um grupo de dados locais e sistematizados que possam auxiliar nas tomadas decisão de distintos setores.

\section{METODOLOGIA}

\section{Dados pluviométricos}

Os dados pluviométricos utilizados consistem no anuais e mensais de precipitação do banco de dados da ANA de estações próximas ao município de Palmas, referentes ao período de 1987 a 2016 . Segundo a ANA, a bacia Araguaia-Tocantins, bacia onde Palmas está inserida, possui 503 estações pluviométricas e para a determinação do regime hidrológico da região foram selecionadas 6 estações, apresentadas a seguir na Tabela 1.

Tabela 1: Estações pluviométricas selecionadas.

\begin{tabular}{llll}
\hline Código & Nome & Município & Responsável \\
\hline 948000 & Miracema do Tocantins & Miracema do Tocantins & ANA \\
1047001 & Novo Acordo & Novo Acordo & ANA \\
1047002 & Porto Gilândia & Monte do Carmo & ANA \\
1048000 & Fátima & Fátima & ANA \\
1048001 & Paraíso do Tocantins & Paraíso do Tocantins & ANA \\
1048005 & Taquarussu do Porto & Palmas & ANA \\
\hline
\end{tabular}

Outros autores utilizaram diferentes bases de dados para estimativa de precipitação em regiões com escassez de estações como, por exemplo, bases dados retiradas da Tropical Rainfall Measuring Mission (TRMM), sendo que as correlações obtidas quando os dados são comparados com as estações pluviométricas são, em sua maioria, muito satisfatórias (CAMPOS, 2017; NÓBREGA et al., 2008; MASSAGLI et al., 2011; MORAIS et al., 2015).

Não obstante, bases de dados como a TRMM são mais complexas, as informações para sua composição são obtidas no site da National Aeronautics and Space Administration (NASA) em formato de rasters e precisam ser trabalhadas em programas de geoprocessamento. Esse tipo de mão de obra e expertise nem sempre está à disposição em todos os municípios, enquanto a base de dados disponibilizada pela ANA é simples, intuitiva e permite o desenvolvimento de análises rápidas e precisas.

Uma parte considerável das estações pluviométricas não possuem séries históricas ou possuem séries incompletas. O primeiro passo tomado na seleção das estações foi desconsiderar as que não possuíam séries históricas, as que possuíam séries com menos de 30 anos de dados e ainda as que não possuíam dados até o ano de 2016. Além dos critérios pré-estabelecidos anteriormente todas as estações escolhidas localizam-se num raio máximo de $500 \mathrm{~km}$ da capital do Estado.

\section{Preenchimento de falhas}

Em todas as estações selecionadas as falhas iniciaram a partir do ano de 2006. Isso se dá principalmente por conta da característica dos dados fornecidos que são classificados em dados brutos e consistidos. Os consistidos são dados que passaram por uma análise prévia da própria Agência de Águas, que elimina medições grosseiras e assegura, em parte sua homogeneidade. Esses dados geralmente são 
anteriores a 2006. Os dados brutos, por sua vez, não passaram por essa análise e, comumente, apresentam disparidades e falhas.

Nas aplicações dos métodos da regressão linear e da ponderação regional com base em regressões lineares para preenchimento de falhas em estudos relacionados aos regimes pluviométricos é recomendado adotar, como critério mínimo, a obtenção de coeficiente de correlação superior a 0,7 entre as estações, valor comumente adotado por outros autores (OLIVEIRA et al., 2010; BARBOSA et al., 2005; PRUSKI et al., 2004).

No presente estudo não foi possível realizar o preenchimento de nenhuma falha, primeiro por não haver correlação superior a 0,7 em nenhuma das estações, e segundo por conta de as falhas serem praticamente todas nos mesmos anos.

Contudo, essas falhas não apresentam padrões, não ocorrem de modo sistemático e são pontuais na região e no período, assim não descaracterizam o estudo e, conforme apontam Baddour et al. (2007), apenas adicionam uma quantidade modesta de incerteza na estimativa da análise.

A fim de atestar a homogeneidade dos dados da série foi realizada a análise da Curva de Dupla Massa, relacionando a estação de referência às médias de precipitações das demais estações observadas.

\section{Precipitação média na bacia e o ano hidrológico}

Em posse dos dados pluviométricos analisados e corrigidos o passo seguinte foi a determinação da precipitação média. O percentual de contribuição de cada uma das estações para o regime hidrológico de Palmas e as precipitações médias foram calculadas pelo Método de Thiessen, metodologia definida por polígonos traçados que delimitam a abrangência de cada estação, esse método é frequentemente utilizado em áreas de grande extensão e onde não existe uma distribuição uniforme de pluviômetros no interior da bacia. Outros autores em pesquisas sobre a dinâmica da precipitação em outras regiões do Brasil utilizaram esse método de modo satisfatório (CASADO et al., 2012; VELLOSO, 2015; MENDES et al., 2019).
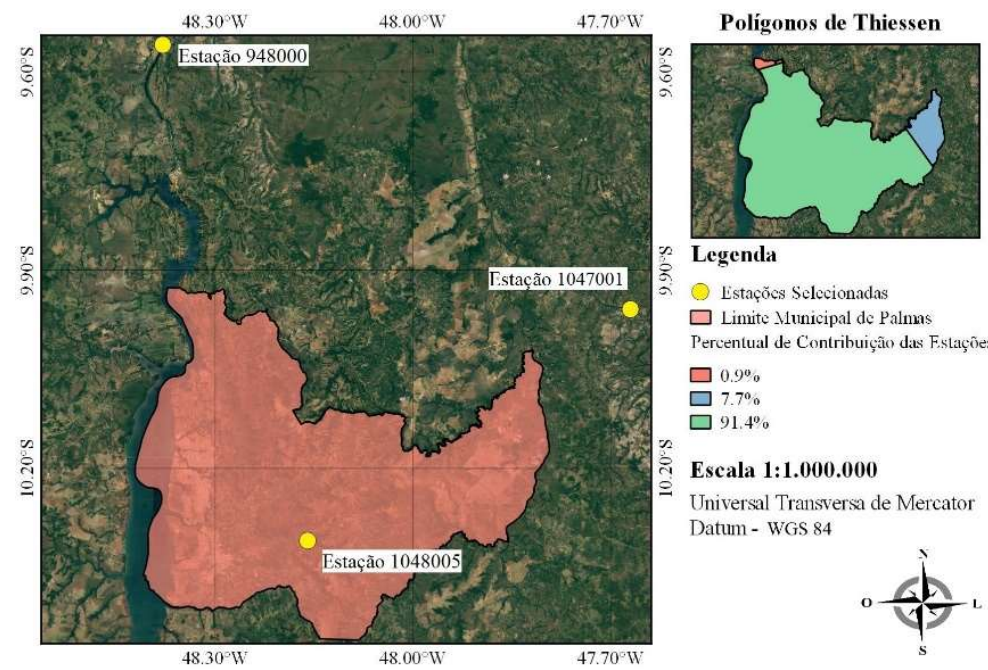

Figura 1: Mapa das estações pluviométricas selecionadas e dos polígonos de Thiessen.

Das estações selecionadas apenas 3 contribuíram significativamente na área do munícipio. As estações selecionadas e a contribuição de cada uma são apresentadas na Figura 1. Duas das estações ficam próximas ao município de Palmas, as estações 948000 e 1047001, e uma dentro do limite municipal, a saber 
a estação 1048005.

As estações que não apresentaram relevância para a área da cidade de Palmas não foram consideradas no cálculo das precipitações médias, portanto o regime hidrológico de Palmas foi determinado apenas a partir das três estações restantes. A estação pluviométrica 1048005, Taquarussu do Porto, é a que mais contribui diretamente dentro da área do município de Palmas. Logo, percebe-se a importância de possuir estações pluviométricas em bom estado e funcionando em áreas estratégicas.

A determinação do ano hidrológico do município de Palmas se deu pela análise dos totais mensais das médias históricas das estações selecionadas no intervalo de 1985 a 2014. Por sua vez, a caracterização do regime pluviométrico do município ocorreu por meio da elaboração de histogramas com valores médios mensais, máximos mensais, totais anuais identificando os eventos críticos de data e lâmina, e pela espacialização das precipitações totais anuais para os períodos seco e chuvoso, nas estações selecionadas no estudo.

\section{RESULTADOS E DISCUSSÃO}

Em todas as estações selecionadas as falhas iniciaram a partir do ano de 2006. Isso se dá principalmente por conta da característica dos dados fornecidos que são classificados em dados brutos e consistidos. Os consistidos são dados que passaram por uma análise prévia da própria Agência de Águas, que elimina medições grosseiras e assegura, em parte sua homogeneidade. Esses dados geralmente são anteriores a 2006. Os dados brutos, por sua vez, não passaram por essa análise e, comumente, apresentam disparidades e falhas.

Em posse dos dados pluviométricos analisados e corrigidos o passo seguinte foi a determinação da precipitação média. O percentual de contribuição de cada estação foi obtido por meio do Método de Thiessen. E das estações selecionadas apenas 3 contribuíram significativamente na área do munícipio. As estações que não apresentaram relevância para a área da cidade de Palmas não foram consideradas no cálculo das precipitações médias, portanto o regime hidrológico de Palmas foi determinado apenas a partir das três estações restantes. É possível notar que a estação 1048005 representa de forma significativa a precipitação de Palmas, caso não houvesse outras estações mais próximas seria possível conduzir um estudo confiável para a cidade com os dados dessa estação. Logo, percebe-se a importância de possuir estações pluviométricas em bom estado e funcionando em áreas estratégicas.

Por meio da análise dos totais mensais das precipitações médias das estações foi possível desenvolver o histograma que representa o ano hidrológico de Palmas. Como é possível observar na Figura 2, a sazonalidade do ano hidrológico está bem definida caracterizada por dois períodos de seis meses cada: o período seco e o chuvoso.

O período seco inicia em maio e se estende até setembro, enquanto o período chuvoso inicia-se em outubro e termina em abril. De acordo com os dados o mês mais chuvoso é dezembro onde os valores de precipitação atingiram 304,8 mm. Esse resultado é muito próximo do encontrado por outros autores que desenvolveram estudos sobre a caracterização hidrológica do Tocantins e da região norte do Brasil. De 
acordo com Marcuzzo et al. (2013) ano hidrológico do Tocantins se inicia em outubro, que é o primeiro mês chuvoso após um período seco, a estação das chuvas tem duração de sete meses, vai de outubro a abril, e a estação de estiagem dura cinco meses, se estendendo de maio a setembro. Souza et al. (2017) em trabalho sobre a caracterização hidrológica do Rio das Fêmeas, na Bahia região próxima ao Tocantins, aponta que a distribuição mensal da precipitação no período de 1985 a 2013 apresenta clara distinção das estações chuvosa e seca; onde o período chuvoso se inicia no mês de setembro, se estendendo até maio, e o período chuvoso retorna a partir de outubro se estendendo até abril.

A Figura 3 apresenta os valores máximos precipitados em casa mês nas três estações. É possível observar a coerência dos dados conforme o ano hidrológico definido.

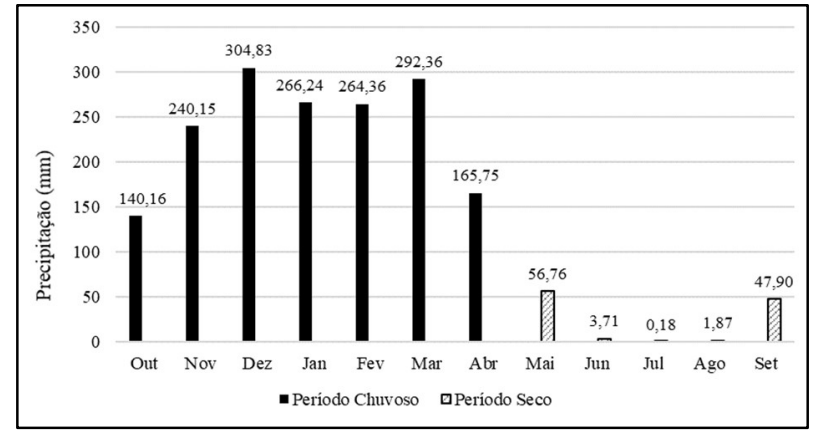

Figura 2: Ano hidrológico de Palmas.

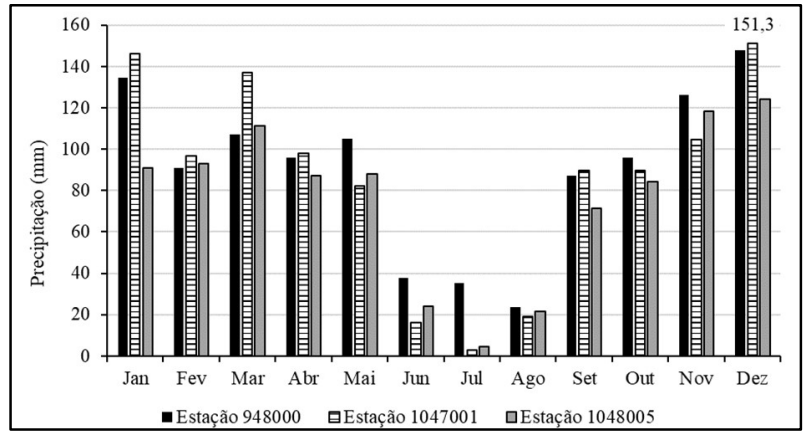

Figura 3: Máximas mensais.

No mês de dezembro a estação 1047001 registrou o máximo volume mensal de precipitação, totalizando 151,3 mm. Além disso, foi possível analisar os valores anuais de precipitação a fim de encontrar os valores máximos ao longo dos anos de registro da série de dados. A Figura 4, apresenta as precipitações totais anuais das três estações de 1986 a 2016.

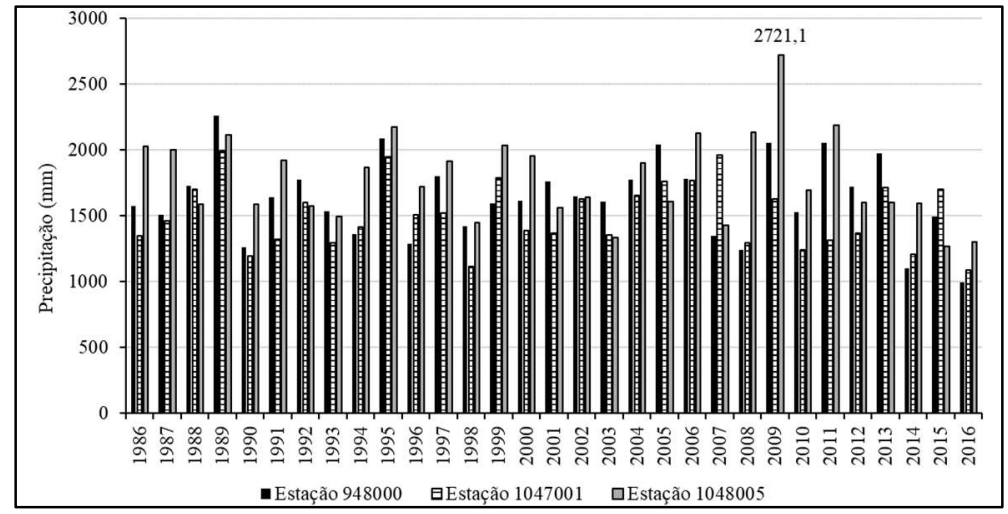

Figura 4: Máximas anuais.

Observa-se que no ano de 2009 a estação 1048005 registrou o maior volume anual precipitado com um total de $2721,1 \mathrm{~mm}$. Esse valor é significativamente superior as médias anuais das demais estações para todo o período de análises, que é de 1637,20 mm.

Os valores médios de precipitação obtidos nesse trabalho para o município de Palmas se mantiveram próximos dos valores habituais registrados em outros trabalhos desenvolvidos ao longo da Bacia TocantinsAraguaia e da região Amazônica, a nível de exemplo cabe citar os trabalhos de Marengo (2003), Aquino et al. (2005), Marcuzzo et al. (2013) e Mendes et al. (2019). 


\section{CONCLUSÕES}

Primeiramente, conclui-se que a metodologia de análise dos dados é recorrente na literatura e as séries histórias podem ser obtidas gratuitamente no portal da ANA de forma simples, intuitiva e sem burocracia, um conjunto de ferramentas e informações que dão possibilidade para impulsionar as pesquisas relacionadas ao tema.

Mediante a análise das séries históricas de precipitação de estações na ANA, no intervalo de 1987 a 2016, foi possível caracterizar o regime pluviométrico do município de Palmas e observar o comportamento da precipitação nesse período de 30 anos. 0 ano hidrológico do município é bem definido, caracterizado por dois períodos distintos de seis meses cada: o período seco e o chuvoso. A consciência dessa transição de períodos é de suma importância para a gestão e o planejamento adequado da drenagem urbana.

O Tocantins é o estado mais novo da Federação e a grande maioria dos seus municípios não possui informações regionalizadas sobre o comportamento das chuvas ao longo do ano, nem tão pouco possui séries históricas de precipitação sistematizadas a disposição para auxiliar nas tomadas de decisão dos gestores municipais. A importância de pesquisas de caráter local ultrapassa o meio científico e pode colaborar no cotidiano, com o crescimento e desenvolvimento de diversas localidades. Deste modo, é de suma importância que mais trabalhos sejam realizados explorando as características meteorológicas regionais do Tocantins a semelhança do que é feito em outras cidades brasileiras.

\section{REFERÊNCIAS}

AQUINO, S.; STEVAUX, J. C.; LATRUBESSE, E. M.. Regime hidrológico e aspectos do comportamento morfohidráulico do rio Araguaia. Revista Brasileira de Geomorfogia, v.6, n.2, p.29-41, 2005.

AYOADE, J. O.. Introdução à climatologia para os trópicos. São Paulo: DIFEL, 1986.

BADDOUR, O.; KONTONGOMDE, H.; TREWIN, B.. The role of climatological normals in a changing climate. Geneva: World Meteorological Organization, 2007.

BARBOSA, S. E. S.; BARBOSA JÚNIOR, A. R.; SILVA, G. Q.; CAMPOS, E. N. B. RODRIGUES, V. C.. Geração de modelos de regionalização de vazões máximas, médias de longo período e mínimas de sete dias para a bacia do Rio do Carmo, Minas Gerais. Revista de Engenharia Sanitária e Ambiental, v.10, n.1, p.64-71, 2005.

BRITTO, F. P.; BARLETTA, R.; MENDONÇA, M.. Regionalização sazonal e mensal da precipitação pluvial máxima no Estado do Rio Grande do Sul. Revista Brasileira de Climatologia, v.3, p.83-99, 2008.

CAMPOS, R. F.. Comparação entre dados de precipitação interpolados e do TRMM (3B43V7). Dissertação (Mestrado em Produção Vegetal) - Universidade Federal do Espírito Santo, Vitória, 2017.

CASADO, G. W.; BARROSO, L. B.; SILVA, F. P.; WOLFF, D. B.; CRUZ, J. C.. Polígonos de Thiessen para a bacia hidrográfica do rio da Várzea, no Rio Grande do Sul. In: CONGRESSO
INTERNACIONAL DE TECNOLOGIAS PARA O MEIO AMBIENTE, 3. Anais. Bento Gonçalves: FIEMA, 2012.

KOBIYAMA, M.; CHECCHIA, T.; SILVA, R. V.. Princípios de hidrologia e hidráulica. Florianópolis: UFSC, 2005.

MARCUZZO, F. F. N.; GOULARTE, E. R. P.. Caracterização do ano hidrológico e mapeamento espacial das chuvas nos períodos úmido e seco do estado do Tocantins. Revista Brasileira de Geografia Física, v.6, n.1, p.91-99, 2013.

MARENGO, J. A.. Condições climáticas e os recursos hídricos no norte brasileiro. In: TUCCI, C. E. M.; BRAGA, B.. Clima e Recursos Hídricos no Brasil. Coleção ABRH, 2003.

MASSAGLI, G. O.; VICTORIA, D. C.; ANDRADE, R. G.. Comparação entre precipitação medida em estações pluviométricas e estimada pelo satélite TRMM. In: CONGRESSO INTERINSTITUCIONAL DE INICIAÇÃO CIENTÍFICA, 5. Anais. Campinas: CIIC, 2011.

MENDES, A. T.; ZUKOWNSKI JUNIOR, J. C.; Caracterização do Regime Pluviométrico do Município de Araguaína - TO. Revista Brasileira de Meteorologia, v.34, n.4, p.449-458, 2019.

MORAES, B. C.; COSTA, J. M. N.; COSTA, A. C. L.; COSTA, M. H.. Variação espacial e temporal da precipitação no estado do Pará. Acta Amazônica, v.35, n.2, p.207-214, 2005.

MORAIS, L. B.; FERREIRA, N. C.. Banco de Dados Pluviométricos Integrados por Dados do Sensor TRMM e 
Estações Pluviométricas no Estado de Goiás. In: SIMPÓSIO BRASILEIRO DE SENSORIAMENTO REMOTO, 17. Anais. João Pessoa: INPE, 2015.

NÓBREGA, R. S.; SOUZA, E. P.; GALVÍNCIO, J. D.. Análise da estimativa de precipitação do TRMM em uma sub-bacia da Amazônia Ocidental. Revista de Geografia, v.25, n.1, p.6-12, 2008.

OLIVEIRA FILHO, J. C.; PINTO, E. S.; SABOYA, L. M. F.; PERSON, A. J.; CAETANO, G. F.. Caracterização do regime pluviométrico da região do projeto Rio Formoso na bacia do Araguaia, TO. Acta Amazônica, v.31, n.2, p.221-221, 2001.

OLIVEIRA, L. F. C.; FIOREZE, A. P.; MEDEIROS, A. M. M.; SILVA, M. A. S.. Comparação de metodologias de preenchimento de falhas de séries históricas de precipitação pluvial anual. Revista Brasileira de Engenharia Agrícola e Ambiental, v.14, n.11, p.1186-1192, 2010.
PRUSKI, F. F.; PEREIRA, S. B.; NOVAES, L. F.; SILVA, D. D.; RAMOS, M. M.. Precipitação média anual e vazão específica média de longa duração, na Bacia do São Francisco. Revista Brasileira de Engenharia Agrícola e Ambiental, v.8, n.2, p.247-253, 2004.

SANTOS, I.; FILL, H. D.; SUGAI, M. R. V. B.; BUBA, H.; KISHI, R. T.; MARONE, E.; LAUTERT, L. F.. Hidrometria aplicada. Curitiba: Instituto de Tecnologia para o Desenvolvimento, 2001.

SOARES, A. S. D.; PAZ, A. R.; PICCILLI, D. G. A.. Avaliação das estimativas de chuva do satélite TRMM no Estado da Paraíba. Revista Brasileira de Recursos Hídricos, v.21, n.2, p.288-299, 2016

SOUZA, N. S.; SOUZA, W. J.; CARDOSO, J. M. S. Caracterização hidrológica e influência da cobertura do solo nos parâmetros de vazão do Rio das Fêmeas. Revista de Engenharia Sanitária e Ambiental, v.22, n.3, p.453-462, 2017.

A CBPC - Companhia Brasileira de Produção Científica (CNPJ: 11.221.422/0001-03) detém os direitos materiais desta publicação. Os direitos referem-se à publicação do trabalho em qualquer parte do mundo, incluindo os direitos às renovações, expansões e disseminações da contribuição, bem como outros direitos subsidiários. Todos os trabalhos publicados eletronicamente poderão posteriormente ser publicados em coletâneas impressas sob coordenação da Sustenere Publishing, da Companhia Brasileira de Produção Científica e seus parceiros autorizados. Os (as) autores (as) preservam os direitos autorais, mas não têm permissão para a publicação da contribuição em outro meio, impresso ou digital, em português ou em tradução. 